\title{
Promoting Neuronal Outgrowth Using Ridged Scaffolds Coated with Extracellular Matrix Proteins
}

\author{
Ahad M. Siddiqui ${ }^{1}{ }^{(\mathbb{D}}$, Rosa Brunner ${ }^{2}$, Gregory M. Harris ${ }^{3} \mathbb{D}$, Alan Lee Miller II ${ }^{4} \mathbb{D}$, Brian E. Waletzki ${ }^{4}$, \\ Ann M. Schmeichel ${ }^{1}$, Jean E. Schwarzbauer ${ }^{3}{ }^{(D}$, Jeffrey Schwartz ${ }^{5}$, Michael J. Yaszemski ${ }^{5}$, \\ Anthony J. Windebank ${ }^{1}$ and Nicolas N. Madigan ${ }^{1, * \mathbb{D}}$
}

\section{check for}

updates

Citation: Siddiqui, A.M.; Brunner, R.; Harris, G.M.; Miller, A.L., II; Waletzki, B.E.; Schmeichel, A.M.; Schwarzbauer, J.E.; Schwartz, J.; Yaszemski, M.J.; Windebank, A.J.; et al. Promoting Neuronal Outgrowth Using Ridged Scaffolds Coated with Extracellular Matrix Proteins. Biomedicines 2021, 9, 479. https://doi.org/10.3390/

biomedicines 9050479

Academic Editor: Petr Krupa

Received: 26 March 2021

Accepted: 23 April 2021

Published: 27 April 2021

Publisher's Note: MDPI stays neutral with regard to jurisdictional claims in published maps and institutional affiliations.

Copyright: (c) 2021 by the authors Licensee MDPI, Basel, Switzerland. This article is an open access article distributed under the terms and conditions of the Creative Commons Attribution (CC BY) license (https:/ creativecommons.org/licenses/by/ $4.0 /)$
1 Department of Neurology, Mayo Clinic, Rochester, MN 55905, USA; siddiqui.ahad@mayo.edu (A.M.S.); schmeichel.ann@mayo.edu (A.M.S.); windebank.anthony@mayo.edu (A.J.W.)

2 Program in Human Medicine, Paracelsus Medical University Salzburg, 5020 Salzburg, Austria; rosa.brunner@stud.pmu.ac.at

3 Department of Molecular Biology, Princeton University, Princeton, NJ 08540, USA; gregory.harris@uc.edu (G.M.H.); jschwarz@princeton.edu (J.E.S.)

4 Department of Orthopaedic Surgery, Mayo Clinic, Rochester, MN 55905, USA; miller.alan@mayo.edu (A.L.M.II); waletzki.brian@mayo.edu (B.E.W.)

5 Department of Chemistry, Princeton University, Princeton, NJ 08544, USA; jschwart@princeton.edu (J.S.); yaszemski.michael@mayo.edu (M.J.Y.)

* Correspondence: madigan.nicolas@mayo.edu

Abstract: Spinal cord injury (SCI) results in cell death, demyelination, and axonal loss. The spinal cord has a limited ability to regenerate, and current clinical therapies for SCI are not effective in helping promote neurologic recovery. We have developed a novel scaffold biomaterial that is fabricated from the biodegradable hydrogel oligo(poly(ethylene glycol)fumarate) (OPF). We have previously shown that positively charged OPF scaffolds (OPF+) in an open spaced, multichannel design can be loaded with Schwann cells to support axonal generation and functional recovery following SCI. We have now developed a hybrid OPF+ biomaterial that increases the surface area available for cell attachment and that contains an aligned microarchitecture and extracellular matrix (ECM) proteins to better support axonal regeneration. OPF+ was fabricated as $0.08 \mathrm{~mm}$ thick sheets containing $100 \mu \mathrm{m}$ high polymer ridges that self-assemble into a spiral shape when hydrated. Laminin, fibronectin, or collagen I coating promoted neuron attachment and axonal outgrowth on the scaffold surface. In addition, the ridges aligned axons in a longitudinal bipolar orientation. Decreasing the space between the ridges increased the number of cells and neurites aligned in the direction of the ridge. Schwann cells seeded on laminin coated OPF+ sheets aligned along the ridges over a 6-day period and could myelinate dorsal root ganglion neurons over 4 weeks. This novel scaffold design, with closer spaced ridges and Schwann cells, is a novel biomaterial construct to promote regeneration after SCI.

Keywords: neuronal outgrowth; cell attachment; Schwann cells; extracellular matrix; scaffolds; spinal cord; axonal regeneration

\section{Introduction}

The spinal cord has a limited ability to regenerate after spinal cord injury (SCI), and available therapies are not efficacious in promoting the recovery of motor and sensory neurological function. The failure to recover function may be due to secondary events that occur after the primary insult such as cell death, axonal loss, demyelination, cyst formation, and an increase in the inhibitory microenvironment [1]. Many therapies are currently under investigation for treating one or more of these secondary events using neuroprotective strategies and cell, regenerative, and rehabilitative therapies [1,2]. A single therapeutic strategy is unlikely to be effective in treating a disorder that is heterogeneous 
in its underlying pathophysiology. Combinatorial treatments that simultaneously address multiple contributions to the residual of the injury will be required.

Biomaterial scaffolds are an attractive platform for combinatorial therapies because they are able to bridge the physical gap produced from gliosis, cyst formation, and cell death by providing structural support for regenerating cells [3,4]. Biomaterials can be combined with extracellular matrices, cells, or pharmaceuticals to promote a more hospitable environment for regeneration $[3,5,6]$. We have developed a positively charged polymer, oligo(poly(ethylene glycol)fumarate) $(\mathrm{OPF}+)$ for scaffold fabrication in a multichannel design that overlays the different tracts of the spinal cord $[4,7]$. OPF+ forms a porous, biodegradable hydrogel that is mechanically similar to the spinal cord [8]. The positive charge on OPF enhanced neuronal cell attachment, extension and the axonal myelination with Schwann cells in vitro [9]. In vivo, OPF+ loaded with Matrigel supported axonal regeneration over 4 weeks [10]. OPF+ scaffolds loaded with Schwann cells further improved axonal regeneration and growth orientation over that seen with Matrigel alone, and they also showed reduced collagen scarring, cyst formation, and proteoglycan accumulation following transection injury $[4,7,10]$. Schwann cells that were genetically modified to express high concentrations of glial cell-derived neurotrophic factor (GDNF-SC) increased axonal regeneration and myelination compared to wild-type Schwann cells and led to enhanced functional recovery following spinal cord transection [5].

Axonal regeneration occurred through the open channels in the scaffold, as well as on the outer surface of the scaffolds. This observation led to the new hypothesis that changing the scaffold architecture to increase the surface area available for axons to regenerate may increase the number of axons regenerating through the scaffold and provide directional guidance. Different scaffold designs have been fabricated with a higher proportion of open to closed spaces in association with a novel ridged surface architecture that would guide regenerating axons. Physical structures for contact-mediated axonal guidance, such as microgrooves or ridges, have been created by laser etching onto polymer surfaces [11-13]. Initial studies using quartz slides microgrooves improved the directional orientation of seeded fibroblast and epithelial cells but did not align chick embryo neurons [11]. Yao et al. (2009) subsequently demonstrated that micro-patterned poly(lactide-co-glycolide) (PLGA) sheets increased neurite alignment. In another study, neonatal rat dorsal root ganglion (DRG) neurons were cultured on grooved polymers of poly(dimethyl siloxane) coated with poly-L-lysine and laminin. On this surface, neurites extended along and arched over the grooves with the somas preferentially adhering to the ridges [14].

The addition of extracellular matrix (ECM) proteins onto polymer surfaces provides sites for receptor-mediated cell attachment to promote axonal guidance and cell migration [15]. Grooved polymers coated with gradients of laminin or collagen have been shown to direct axonal growth cones $[16,17]$. Fibronectin promotes Schwann cell proliferation and motility in culture [18], and it is an attractive ECM candidate to make biomaterials more cell adhesive and facilitate growth. Peripheral nerve regeneration in rats can be enhanced by the addition of fibronectin and Schwann cells in alginate hydrogels [19]. Fibronectin has also been shown to help increase serotonergic axon sprouting and can influence axonal growth when used in combination with cells, growth factors, and biomaterials [20,21].

In this study, we sought to determine which ECM molecules best support neuronal attachment and whether the structural microarchitecture may further improve the directional alignment of axonal extension and myelination in vitro. A novel hybrid OPF+ scaffold design was fabricated as a ridged, flat sheet and coated with ECM proteins. Upon hydration, the sheets had the unique property of spontaneously rolling into a spiral 3D configuration. Polymer sheets with ridge spacings of $0.2,0.4$, or $1 \mathrm{~mm}$ apart were coated with laminin, collagen, or fibronectin, and then, they were used in in vitro assays to quantitate neuronal attachment, DRG neurite extension, and axonal myelination by Schwann cells. 


\section{Material and Methods}

\subsection{OPF Synthesis and OPF+ Scaffold Fabrication}

$\mathrm{OPF}+$ was synthesized as described previously $[8,9]$. To create the ridged OPF+ sheet, liquid polymer was pipetted onto a Teflon mold that contained micro-grooves $100 \mu \mathrm{m}$ in depth and spaced 1, 0.4, and $0.2 \mathrm{~mm}$ apart. A glass slide was placed on top with a $0.08 \mathrm{~mm}$ thick spacer. The sheets were polymerized by exposure to an ultra-violet (UV) light (365 $\mathrm{nm}$ ) for one hour and cured overnight. Single channel OPF+ scaffolds were fabricated by mold injection of the polymer and cast over a $1 \mathrm{~mm}$ wire prior to UV exposure. The scaffolds were cut into $2 \mathrm{~mm}$ lengths for transplantation.

\subsection{Swelling Ratio}

Desiccated, ridged OPF+ sheets were cut into $6 \times 6 \mathrm{~mm}$ pieces and weighed dry $\left(\mathrm{W}_{\mathrm{d}}\right)$ and following hydration in distilled water for $24 \mathrm{~h}$ ( $\mathrm{W}_{\mathrm{s}}$; swollen weight).

The swelling ratio was calculated using the equation:

$$
\text { Swelling ratio }=\frac{(\mathrm{Ws}-\mathrm{Wd})}{\mathrm{Wd}} .
$$

\subsection{OPF+ Sheet Culture Preparation and ECM Protein Coating}

$\mathrm{OPF}+$ sheets were sterilized by immersion in serial dilution of ethanol, rehydrated in cell culture media, and then pinned flat onto sterile culture dishes containing a layer of silicone elastomer (SYLGARD ${ }^{\circledR} 184$ Silicone Elastomer Kit; Dow Corning, Midland, MI, USA). The OPF+ sheets containing ridges spaced $1 \mathrm{~mm}$ apart were coated with rat tail collagen 1 (3.36 mg/mL; Corning ${ }^{\circledR}$, New York, NY, USA), laminin $(100 \mu \mathrm{g} / \mathrm{mL}$; SigmaAldrich ${ }^{\circledR}$, St. Louis, MO, USA), or rat plasma fibronectin $(10 \mu \mathrm{g} / \mathrm{mL})$ overnight at $37^{\circ} \mathrm{C}$. Control sheets received no additional ECM protein coating other than that which would be present in the serum of the media (referred to as serum coated). The fibronectin was purified by gelatin-Sepharose affinity chromatography from frozen rat plasma [6]. Then, the sheets were washed 3 times to remove unabsorbed ECM proteins. To determine the effect of dissociated DRG attachment and alignment on OPF+ sheets with different ridge sizes, OPF+ sheets with ridges $0.2,0.4$, and $1 \mathrm{~mm}$ apart were coated with laminin.

\subsection{Whole DRG Explants}

DRG neurons were isolated from Sprague-Dawley pups on embryonic day 15 as previously described [22]. All procedures were approved by the Mayo Clinic Institutional Animal Care and Use Committee (A00002147-16, last approved: 8/30/2019), and all guidelines were followed in accordance with the National Institute of Health, Institute for Laboratory Animal Research and the United States Public Health Services Policy on the Humane Care and Use of Laboratory Animals. Whole DRG were placed on the scaffold in media containing modified Eagle's medium (MEM; Gibco-BRL, Gaithersburg, MD, USA) supplemented with $10 \%$ calf bovine serum (CBS) (HyClone, Logan, UT, USA), L-glutamine (1.2 mM; Gibco, Carlsbad, CA, USA), glucose $(7 \mathrm{mg} / \mathrm{mL}$; Sigma Aldrich, St. Louis, MO, USA), and nerve growth factor (NGF, $5 \mathrm{ng} / \mathrm{mL}$; Harlan Bioproducts, Indianapolis, IN, USA). Initially, the explants were incubated for $1 \mathrm{~h}$ at $37^{\circ} \mathrm{C}$ in $150 \mu \mathrm{L}$ media to allow them time to attach. Once the DRG explants were attached, the plate was filled with media.

Eighteen DRGs for each condition were plated with 4-6 DRGs per scaffold. DRG explants were imaged at 24 and $48 \mathrm{~h}$ after isolation using a Zeiss Axiovert Model 35 microscope with a Nikon CCD camera (Carl Zeiss Inc., Oberkochen, Germany). The length of the longest neurite of each DRG was analyzed by measuring from the edge of the DRG to the end of the longest outgrowing neurite using Image J (v 1.52, National Institute of Health; https:/ /imagej.nih.gov/ij/). Given a variable degree of DRG attachment on each type of substrate, the final numbers of explants available for analysis was $n=17$ DRGs for laminin, $n=11$ DRGs for collagen, $n=11$ DRGs for fibronectin, and $n=4$ DRGs for serum coated. 


\subsection{DRG Neuronal Cultures}

Dissociated DRG neurons were isolated from Sprague-Dawley pups on embryonic day 15 as previously described [22]. Approximately 100-200 whole DRGs were pooled and dissociated using trypsin and mechanical trituration. A total of 50,000 cells were plated onto each scaffold sheet, and they were grown in MEM supplemented with 15\% CBS (HyClone, Logan, UT, USA), L-glutamine (1.2 mM; Gibco, Carlsbad, CA, USA), glucose $(7 \mathrm{mg} / \mathrm{mL}$; Sigma Aldrich, St. Louis, MO, USA), and NGF (5 ng/mL; Harlan Bioproducts, Indianapolis, IN, USA). Dissociated cultures were treated for 3 days with $1 \times 10^{-5} \mathrm{M}$ 5-fluoro-2-deoxy-uridine and with $1 \times 10^{-5} \mathrm{M}$ uridine (Sigma Aldrich, St. Louis, MO, USA) to remove non-neuronal cells $[23,24]$. The cells were fixed with $4 \%$ paraformaldehyde for $30 \mathrm{~min}$ and stored in phosphate-buffered saline (PBS) at $4{ }^{\circ} \mathrm{C}$ for immunocytochemistry.

\subsection{Immunocytochemistry}

The fixed OPF+ sheets were blocked with $10 \%$ normal donkey serum and $0.1 \%$ Triton $X-100$ in 0.01 M PBS for 30 min. Primary antibodies against mouse anti- $\beta$-III tubulin (1:300, Millipore, Temecula, CA, USA) and rabbit anti-myelin basic protein (1:800, Abcam, Cambridge, UK) were diluted in PBS containing 5\% normal donkey serum and $0.3 \%$ Triton X-100 at $4{ }^{\circ} \mathrm{C}$ overnight. Secondary antibodies (donkey anti-mouse Cy3; Millipore Chemicon, Temecula, CA, USA; 1:200 and donkey anti-rabbit Alexa 647; Jackson ImmunoResearch Laboratories West Grove, PA, USA; 1:200) were diluted with 5\% normal donkey serum and $0.3 \%$ Triton-X-100 in PBS. After removing the pins, the OPF+ sheets were carefully placed onto a glass slide using forceps with the ridges facing upwards. Glass coverslips were mounted using Slow Fade Gold Antifade Reagent with DAPI nuclear stain (Molecular Probes $^{\circledR}$, Eugene, OR, USA).

\subsection{Image Analysis of DRG Neurons}

All images of dissociated neurons were taken using an inverted fluorescence microscope Zeiss Axio Observer Z-1 with a motorized stage (Carl Zeiss, Inc., Oberkochen, Germany) mounted with an Axiocam 503 camera (Carl Zeiss, Oberkochen, Germany). Pictures were acquired via the ZEN 2 (blue edition) imaging software (Carl Zeiss, Oberkochen, Germany). For cell quantification, z-stacks with approximately 5 slices at magnification of $10 \times$ were taken using an EC Plan-Neofluar $10 \times / 0.30 \mathrm{Ph} 1$ objective. On each polymer sheet, 4 representative areas of different ridges and the adjacent flat parts were systematically captured. To avoid bias, the regions were chosen by moving one field of view up or down from the centered position and then 2 fields across left or right to yield a total of 4 quadrants. The DRG neurons preparation was repeated at least 3 times. Cell nuclei (DAPI), which were associated with axons ( $\beta$-tubulin, red), were counted in each image in an area of $878.94 \mu \mathrm{m} \times 662.84 \mu \mathrm{m}$ on the polymer to quantify neuronal cell attachment.

In order to determine the ECM protein coating that displayed the most neurite outgrowth and attachment, the amount of $\beta$-III tubulin was calculated for each polymer sheet using ImageJ software by measuring the mean gray value of the staining. The amount of $\beta$-tubulin staining was normalized to the amount of DAPI (mean gray value) per cell. A mean value of normalized $\beta$ - tubulin mean gray values was derived for each polymer sheet from replicates of the 4 fields of views. For comparison between different ECM molecules on OPF+ sheets with $1 \mathrm{~mm}$ spaced ridges, laminin-coated sheets had $n=7$ sheets, fibronectin-coated sheets had $n=3$ sheets, collagen-coated sheets had $n=4$ sheet, and sheets with no substrate had $n=6$ sheets. For different spaced ridges, OPF + sheets with $0.2 \mathrm{~mm}$ spaced ridges had $n=3$ sheets, $0.4 \mathrm{~mm}$ spaced ridged sheets had $n=2$ sheets, and $1 \mathrm{~mm}$ ridged sheets had $n=4$ sheets.

\subsection{Schwann Cell Cultures}

Primary rat Schwann cells were isolated from sciatic nerves of 2-5-day-old SpragueDawley pups, as previously described $[25,26]$. A total of 125,000 cells were seeded on to laminin-coated OPF+ ridged sheets. Schwann cells were imaged using Zeiss Axiovert 
Model 35 microscope with a Nikon CCD camera (Carl Zeiss, Oberkochen, Germany) at $24 \mathrm{~h}$ and 6 days. For each condition, 3 scaffold replicates were made, and images were taken of 4 fields of views per scaffold.

\subsection{Neuronal-Schwann Cell Co-Culture}

Schwann cells and dissociated DRG neurons were isolated and plated together (1:1 ratio, 100,000 cells in total per scaffold) on OPF+ ridged sheets. The cells were cultured for 4 weeks in MEM supplemented with 15\% CBS (HyClone, Logan, UT, USA), L-glutamine (1.2 mM; Gibco, Carlsbad, CA, USA), glucose (7 mg/mL; Sigma Aldrich, St. Louis, MO, USA) and NGF ( $5 \mathrm{ng} / \mathrm{mL}$; Harlan Bioproducts, Indianapolis, IN, USA), $50 \mu \mathrm{g} / \mathrm{mL}$ of ascorbic acid (Sigma Aldrich, St. Louis, MO, USA), and $2 \mu \mathrm{M}$ Forskolin (Sigma Aldrich, St. Louis, MO, USA ). For each condition, 3 scaffold replicates were made, and images were taken of 4 fields of views per scaffold using a Zeiss LSM780 confocal microscope system (Carl Zeiss, Oberkochen, Germany).

\subsection{Statistics}

All data are reported as mean \pm standard error of the mean (SEM). All statistics were calculated using GraphPad Prism 7 (GraphPad Software, Inc., San Diego, CA, USA). Statistical significance was calculated using one-way ANOVA with multiple comparisons using Tukey's post-hoc testing (unless stated otherwise). On graphs, $p$-values are represented as ${ }^{*} p<0.05,{ }^{* *} p<0.01,{ }^{* * *} p<0.001$, and ${ }^{* * * *}$ or \#\#\# $p<0.0001$.

\section{Results}

\subsection{Ridged $O P F+$ Sheet Characterization}

First, $0.08 \mathrm{~mm}$ thick OPF+ sheets were embedded with longitudinal ridges spaced 0.2, 0.4 , or $1 \mathrm{~mm}$ apart (Figure 1A). Our previously used scaffold was fabricated with seven channels that were $2 \mathrm{~mm}$ wide and $32 \mathrm{~mm}$ long (Figure 1B). Swelling ratios were calculated to be $10.5 \pm 0.8$ for OPF+ sheets with $1 \mathrm{~mm}$ spaced ridges, $9.8 \pm 0.4$ for sheets with $0.4 \mathrm{~mm}$ spaced ridges, and $9.7 \pm 0.1$ for sheets with $0.2 \mathrm{~mm}$ spaced ridges (Figure 1C). Hydrated sheets spontaneously rolled into a spiral configuration (Figure 1D,E). In comparison to a multichannel scaffold (Figure 1B), the rolled-sheet design allowed for a greater volume of open space inside of the scaffold and increased surface area that was dependent on the number of loops in the spiral (Figure 1F,G). Internal volumes and surface areas were calculated by taking into account the number of channels that form between ridges, ridge separation $(\mathrm{mm})$, length of the cylinder $(\mathrm{mm})$, and ridge width $(\mathrm{mm})$ (Figure $1 \mathrm{~F})$. A scaffold sheet with $3 \times$ loops increased the volume by 2.6 fold $\left(3.34 \mathrm{~mm}^{3}\right.$ to $\left.8.83 \mathrm{~mm}^{3}\right)$, whereas a sheet with $4 \times$ loops has an increase of approximately 3 fold $\left(3.34 \mathrm{~mm}^{3}\right.$ to $\left.9.72 \mathrm{~mm}^{3}\right)$ compared to the seven multichannel OPF+ scaffold design (Figure 1F). There was a similar corresponding increase in surface area where sheets with $3 \times$ loops had 1.71 fold increase $\left(45.4 \mathrm{~mm}^{2}\right.$ to $\left.77.7 \mathrm{~mm}^{2}\right)$ and $4 \times$ loops had 2.87 fold increase $\left(45.4 \mathrm{~mm}^{2}\right.$ to $\left.130.5 \mathrm{~mm}^{2}\right)$ compared to the seven channel design.

\subsection{Whole DRG Neurite Outgrowth Is Enhanced on Laminin-Coated Sheets}

Whole DRGs were used to determine the effect of different ECM protein coatings (laminin, fibronectin, and collagen) on promoting neurite outgrowth on OPF+ sheets with ridges $1 \mathrm{~mm}$ apart. The explants were observed to consistently settle on or immediately adjacent to a ridge, rather than on the broader, flat intervening surfaces (Figure 2). The DRGs elongated along the ridge and into the adjacent areas in conditions where ECM protein coatings were present in contrast to $\mathrm{OPF}+$ sheets with serum coating. Within $24 \mathrm{~h}$ of culture, laminin-coated $\mathrm{OPF}+$ sheets had longer neurite outgrowth $(708.5 \pm 34.93 \mu \mathrm{m}$, Figure 2E) than controls with serum coating only $(255.7 \pm 37.12 \mu \mathrm{m}, p=0.004)$, fibronectin $(288.3 \pm 33.72 \mu \mathrm{m}, p<0.0001)$, and collagen (433.6 $\pm 74.56 \mu \mathrm{m}, p=0.0362)$. Outgrowth from collagen and fibronectin was not significantly different from serum-coated control surfaces. After $48 \mathrm{~h}$ of culture, laminin-coated OPF+ sheets $(1261 \pm 58.98 \mu \mathrm{m}, p<0.0001)$ contin- 
ued to support greater neurite outgrowth than serum-coated control (445.1 $\pm 61.15 \mu \mathrm{m})$, fibronectin (731.9 $\pm 69.99 \mu \mathrm{m}, p<0.0001)$, and collagen $(817.3 \pm 89.9 \mu \mathrm{m}, p<0.0001)$, with collagen and fibronectin not significantly different to serum-coated control.
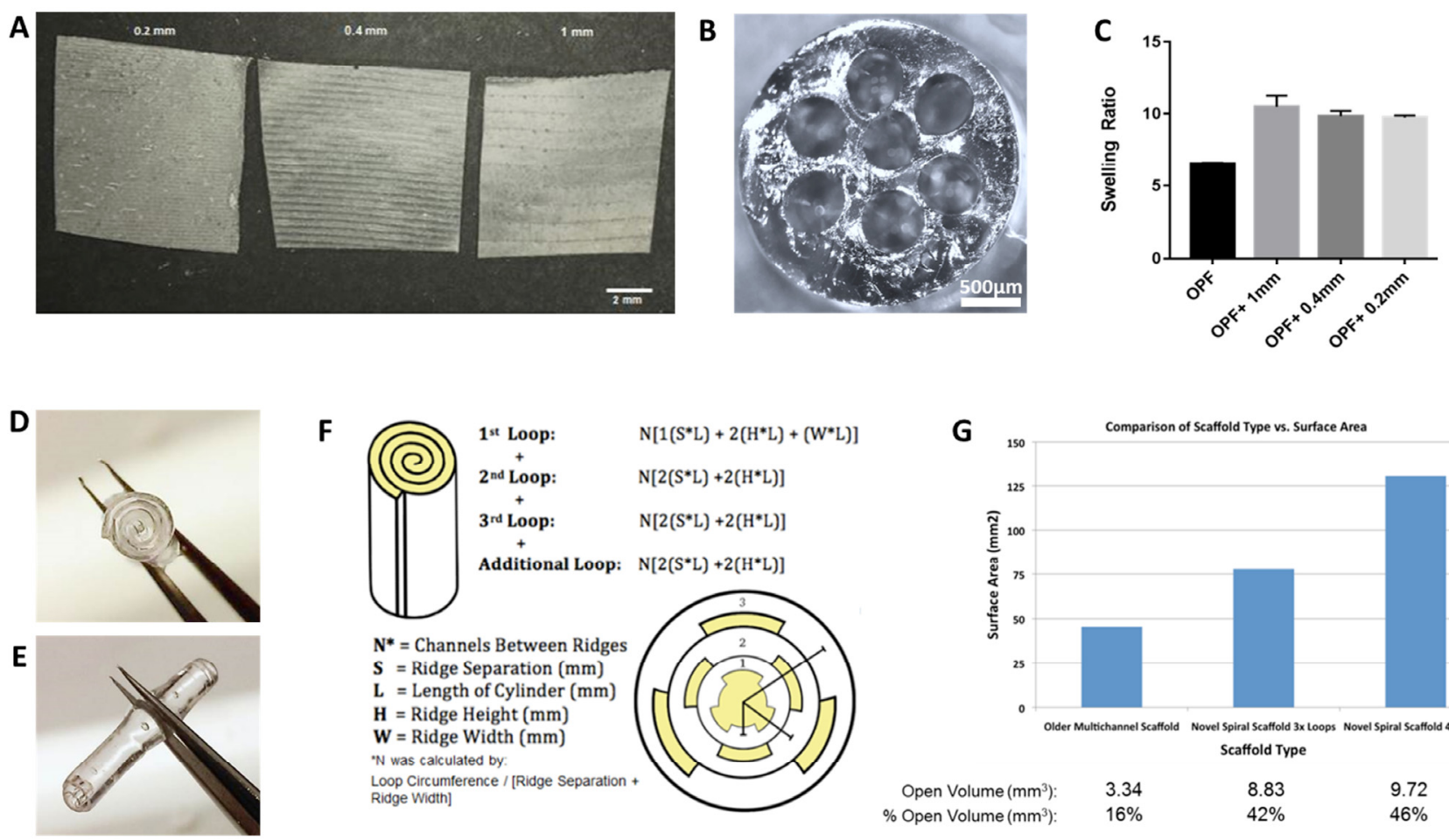
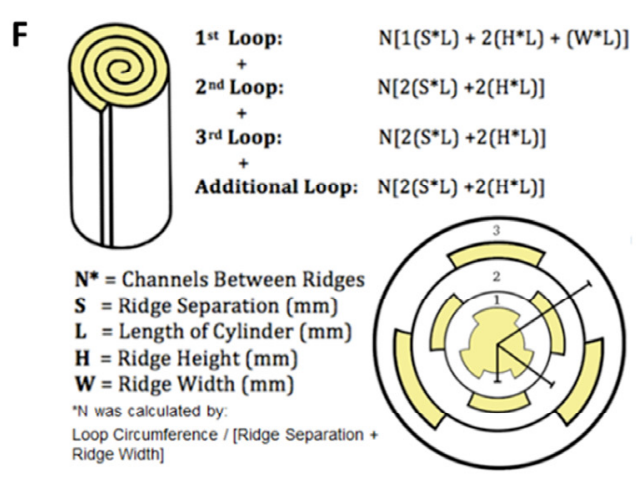

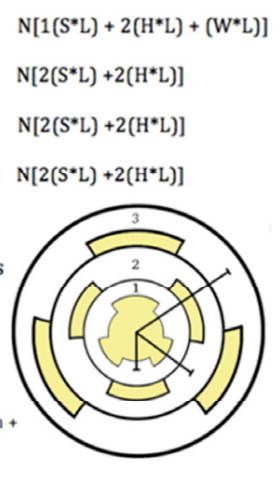

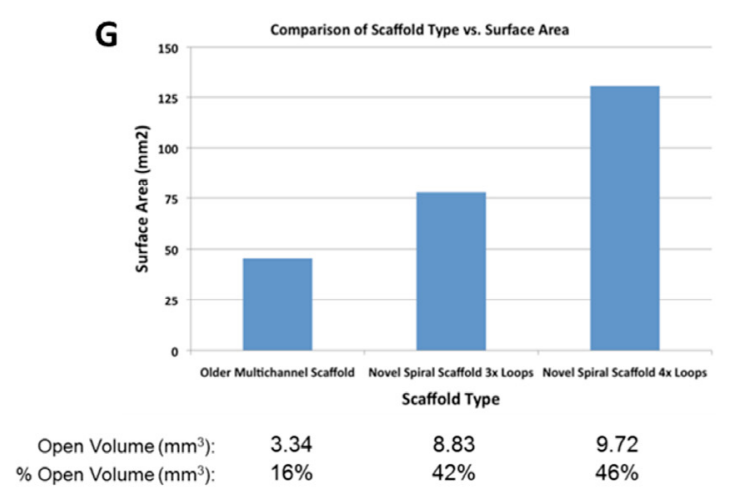

G $\%$ Open Volume $\left(\mathrm{mm}^{3}\right)$

Figure 1. Ridged OPF+ sheet fabrication and characteristics. (A) After crosslinking of OPF polymer on Teflon molds, OPF+ sheets contain $100 \mu \mathrm{m}$ high ridges that are spaced $0.2,0.4$, and $1 \mathrm{~mm}$ apart. (B) OPF+ has previously been fabricated as a multichannel scaffold with seven channels and is as wide as a rat spinal cord. We previously demonstrated that axons grow through the channels, as well as the outside surface [5]. (C) The swelling ratios of OPF+ sheets were similar to each other and greater than the OPF neutral charged sheet. Bars represent mean \pm SEM. (D) and (E) When the ridged scaffold is rehydrated, it spontaneously rolls up into a 3D configuration along the axis of the ridges. (F) Schematic and mathematical modeling demonstrating the calculation of surface area of the scaffold ridged sheet. $(\mathbf{G})$ The surface area and volumes both show a substantial increase compared to the multichannel scaffold configuration. The $1 \mathrm{~mm}$ ridged sheets with three to four loops maximize the area available for growth.

The outgrowth rate $(\mu \mathrm{m} / \mathrm{h})$ of whole DRG neurites over $48 \mathrm{~h}$ in culture between the different ECM coatings (Figure $2 \mathrm{~F})$ was compared. In the first $24 \mathrm{~h}$, laminin $(29.52 \pm 1.45 \mu \mathrm{m} / \mathrm{h}$, $p=0.017$ ) enabled a higher rate of neurite outgrowth than was observed on OPF+ sheets with serum coating $(10.66 \pm 1.55 \mu \mathrm{m} / \mathrm{h})$. There was no significant difference between the outgrowth rates of fibronectin $(11.64 \pm 1.46 \mu \mathrm{m} ; p=0.9977)$ and collagen $(18.07 \pm 3.11 \mu \mathrm{m} / \mathrm{h}$; $p=0.9065)$ compared to serum coating. In the next $24 \mathrm{~h}$, there were no significant differences between laminin $(23.03 \pm 2.85 \mu \mathrm{m} / \mathrm{h} ; p=0.1120)$, fibronectin $(17.64 \pm 2.8 \mu \mathrm{m} / \mathrm{h}$; $p=0.6721)$, and collagen $(15.99 \pm 4.87 \mu \mathrm{m} / \mathrm{h} ; p=0.8394)$ as compared with serum coating $(7.88 \pm 2.98 \mu \mathrm{m} / \mathrm{h})$.

\subsection{Dissociated DRG Neuron Neurite Outgrowth Is Enhanced on Laminin-Coated Sheets}

$\mathrm{OPF}+$ sheets with ridges $1 \mathrm{~mm}$ apart and laminin, fibronectin, or collagen ECM supported dispersed neuronal cell attachment and outgrowth. On all surfaces, dissociated neurons preferentially attached to the ridges and aligned their axons longitudinally along the ridge (Figure 3 and Figure S1). The use of laminin, fibronectin, or collagen increased the number of adherent neurons on the ridge by $3.4 \pm 0.62$ fold, $2.69 \pm 0.50$ fold, and $3.7 \pm 0.32$ fold, respectively over ridged sheets with serum coating (Figure 3E). The use of laminin resulted in a greater increase in neuronal attachment $(38.1 \pm 5.98$ fold $)$ in the spaces 
between the ridges compared to collagen coating ( $4.25 \pm 3.3$ fold) $(p=0.003$; Figure $3 \mathrm{~F})$. Neuronal attachment in between the ridges on fibronectin-coated sheets (32.36 \pm 5.65 fold, $p=0.013)$ was also greater statistically than those attached on collagen-coated sheets. A total of $71.67 \pm 10.76 \%(p=0.0127)$ of neurons attached to the ridges on laminincoated sheets, $60.33 \pm 10.67 \%(p=0.0374)$ attached to the ridges on fibronectin-coated sheets, $98.33 \pm 12.32 \%(p<0.0001)$ attached to the ridges on collagen-coated sheets, and $94.33 \pm 12.32 \%(p<0.0001 ; 2$-way ANOVA/Sidak's multiple comparison) attached to the ridges on serum-coated sheets, demonstrating a preferential neuronal attachment onto the ridge (Figure $3 G)$.
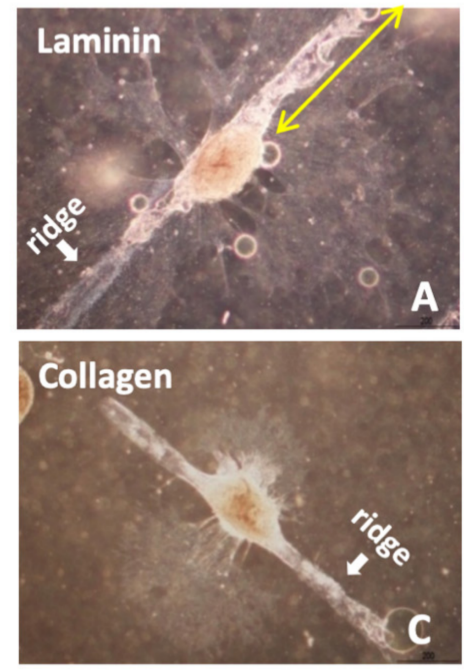
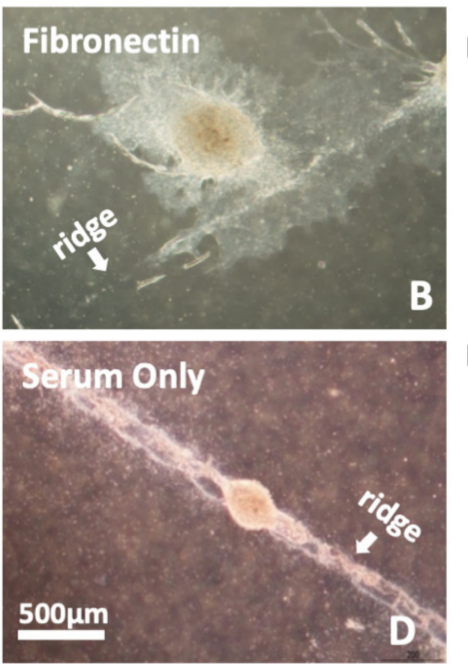

E
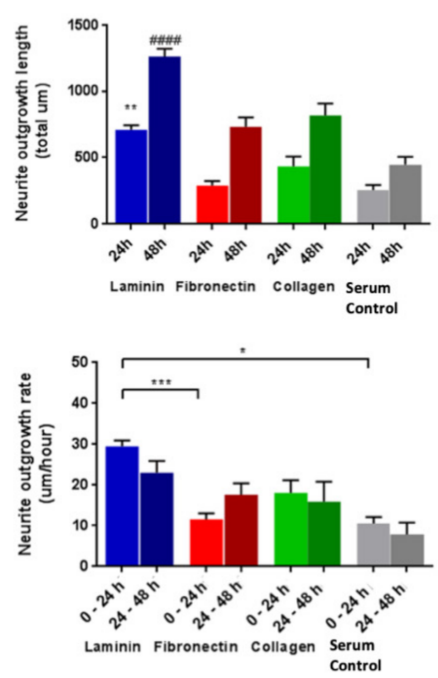

Figure 2. Whole DRG explants on $1 \mathrm{~mm}$ spaced $\mathrm{OPF}+$ sheets $48 \mathrm{~h}$ after culture (phase contrast images each at $2.5 \times$ magnification). DRGs were grown on sheets coated with (A) laminin, (B) fibronectin, (C) collagen, or (D) serum only. It was observed that the explants prefer to attach near or on the ridges, and neurites can be observed aligning on the ridge. The long neurite length was measured (yellow arrow). (E) Neurite length of DRG explants on differently coated OPF+ sheets 24 and $48 \mathrm{~h}$ after culture ${ }^{* *} p<0.01$ compared to $24 \mathrm{~h}$ on serum-coated sheets; \#\#\# $p<0.0001$ compared to $48 \mathrm{~h}$ on serum-coated sheets). Laminin-coated sheets displayed significantly longer neurite outgrowth of DRG explants after $24 \mathrm{~h}$ and $48 \mathrm{~h}$ of culture. (F) Neurite outgrowth rates in the first and second $24 \mathrm{~h}$ after culture on differently coated $1 \mathrm{~mm}$ spaced $\mathrm{OPF}+$ sheets. Neurite outgrowth rate in the first $24 \mathrm{~h}$ of culture of DRG explants on laminin-coated sheets were significantly higher than on fibronectin-coated and serum only-coated sheets. ${ }^{*} p<0.05,{ }^{* * *} p<0.001$. Data represent means $\pm \mathrm{SEM}$.

The neurite density of dissociated neurons was also greater on laminin and fibronectincoated sheets (Figure $3 \mathrm{H}$ ), as measured by the stereologic analysis of the areas of $\beta$-tubulin staining. Laminin-coated sheets $(185.3 \pm 41.02$ mean gray value; $p=0.002)$ and fibronectin (198.4 \pm 30.14 mean gray value; $p=0.0408)$ had higher total $\beta$-tubulin staining per cell than sheets with serum coating $(20.73 \pm 5.59$ mean gray value). The neurite density on laminin-coated sheets $(p=0.0263)$ and fibronectin-coated sheets $(p=0.0408)$ was also greater than that seen on collagen-coated sheets.

\subsection{Increasing the Number of Ridges Improves Neuronal Cell Attachment, Alignment, and Neurite Density}

To determine what effect ridge spacing distance may have on neuronal cell attachment and alignment, laminin-coated $\mathrm{OPF}+$ sheets with ridges $0.2,0.4$, and $1 \mathrm{~mm}$ apart were used. Tighter ridge spacing increased the number of ridges per area and the overall surface area of the sheet (Figure 4A-C), which in turn improved neuronal cell attachment. Many of the cells settled around or on top of the ridges, extending neurites along the ridge. The number of neuronal cells located on the ridge surface was 2.5 fold greater for the $0.2 \mathrm{~mm}$ spaced OPF+ sheets (Figure 4D; $208.6 \pm 44.3$ cells; $p=0.039$ ) than the $1 \mathrm{~mm}$ OPF+ sheets $(84.8 \pm 15.1$ cells). The $0.4 \mathrm{~mm}$ OPF+ sheets (Figure 4D; $186.4 \pm 11.9$ cells; $p=0.1215$ ) had 
a 2-fold greater number of cells than the $1 \mathrm{~mm}$ spaced $\mathrm{OPF}+$ sheets. The neurite density was increased on the OPF+ sheets with ridges more closely spaced $(0.2 \mathrm{~mm}$ and $0.4 \mathrm{~mm}$ apart). We found a 2.9 fold increase in the amount of $\beta$-III tubulin staining (normalized to the amount of DAPI staining/cell) when comparing OPF+ sheets with $0.2 \mathrm{~mm}$ spaced ridges (Figure $4 \mathrm{E} ; 719.5 \pm 130.3$ mean gray value; $p=0.012$ ) to $\mathrm{OPF}+$ sheets with $1 \mathrm{~mm}$ spaced ridges (251.2 \pm 33.4 mean gray value).
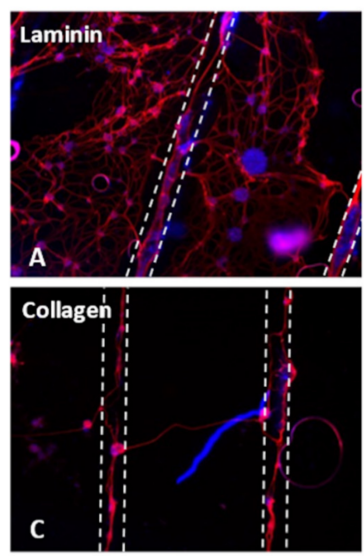
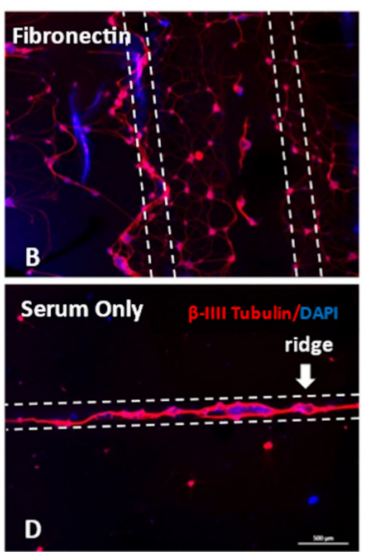
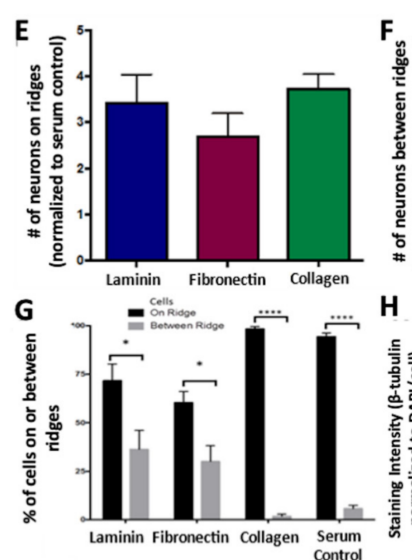
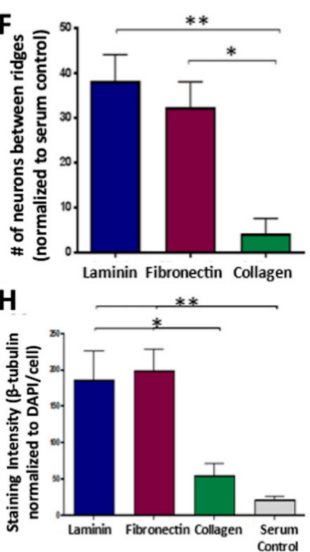

Figure 3. Attachment, alignment, and outgrowth of dissociated DRG neurons on coated OPF+ sheets with ridges $1 \mathrm{~mm}$ apart. Immunofluorescent images of b-III tubulin stained axons show attachment and outgrowth from neurons near or on the ridges on OPF+ sheets coated with (A) laminin, (B) fibronectin, (C) collagen, or (D) serum only. The neurites preferentially aligned on the ridges (located between the dotted white lines). The neurons are stained with $\beta$-III-Tubulin (red) with a DAPI (blue) counter stain. (E) The number of neurons on ridges (normalized to the number of cells on the ridges with no substrate) of $\mathrm{OPF}+$ sheets coated with laminin, fibronectin, and collagen. (F) The number of cells in between the ridges (when normalized to OPF+ sheets with serum only). (G) Percent of cells on ridges or in between ridges for each condition. (H) Neurite density as measured by staining intensity (mean gray value) of $\beta$-III-Tubulin normalized to the mean gray value of DAPI/cell. ${ }^{*} p<0.05,{ }^{* *} p<0.01,{ }^{* * *} p<0.0001$. Data represent means $\pm \mathrm{SEM}$.
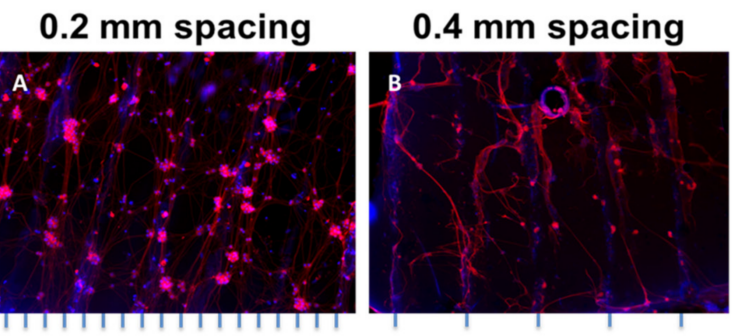

\section{$1 \mathrm{~mm}$ spacing}
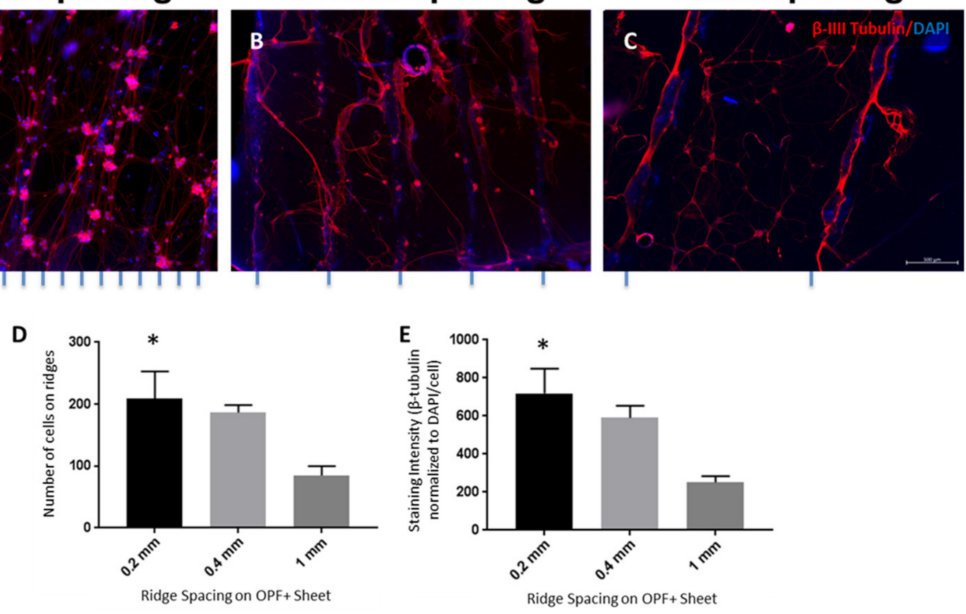

Figure 4. Alignment, attachment, and neurite density of disassociated DRG neurons on OPF+ sheets with ridges spaced $0.2,0.4$, and $1 \mathrm{~mm}$. The neurons were labeled using $\beta$-III tubulin (red) and DAPI (blue). When the ridges are spaced closer together, such as $0.2 \mathrm{~mm}$ apart (A) or $0.4 \mathrm{~mm}$ apart (B), there are more neurites observed aligned along the ridges than the $1 \mathrm{~mm}$ spaced sheets (C). (D) Number of cells on the ridges of the OPF+ scaffolds. (E) $\beta$-III tubulin staining intensity (normalized to DAPI/cell) of neurons grown on $\mathrm{OPF}+$ sheets with ridges spaced $0.2,0.4$, and $1 \mathrm{~mm}$ apart. ${ }^{*} p<0.05$ compared to $1 \mathrm{~mm}$ spacing as control. Data represent means \pm SEM. 


\subsection{The Number of Ridges Influences Schwann Cell Organization and Axonal Myelination}

In our previous studies, we have loaded the multichannel scaffolds with genetically modified Schwann cells, which facilitated axonal regeneration and recovery after spinal cord transection [5]. We next sought to demonstrate that the OPF+ ridged sheet design with laminin coating would support the growth of Schwann cells. Schwann cells on $\mathrm{OPF}+$ ridged sheets initially formed a cell layer in a dispersed and unorganized manner (Figure 5A-C). Over a 6-day period, the Schwann cells organized along the ridges of the scaffold (Figure 5D-F). When the Schwann cells were co-cultured with dispersed DRG neurons for 4 weeks, neurites became myelinated (Figure 6). Neurites aligned well with the ridges and stained positively for myelin basic protein (MBP). Greater densities of aligned myelinated neurites were observed when the ridges were spaced closer together $(0.2 \mathrm{~mm}$ spacing vs. $1 \mathrm{~mm}$ spacing).
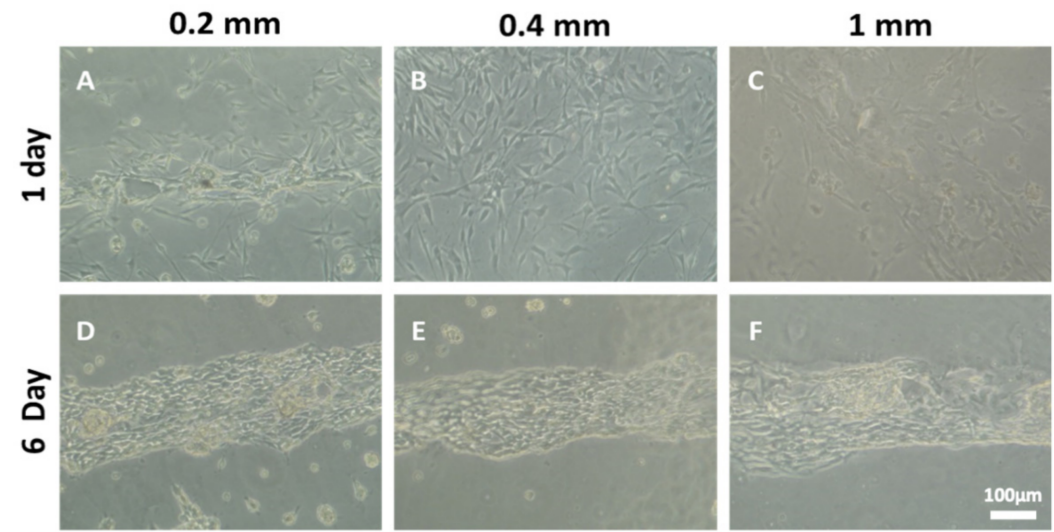

Figure 5. Bright field images (each at $10 \times$ magnification) of primary rat Schwann cells grown on $\mathrm{OPF}+$ sheets with ridges $0.2,0.4$, and $1 \mathrm{~mm}$ apart. One day after culture the Schwann cells cover the sheet in an unorganized manner (A-C). However, 6 days after culture, the Schwann cells are aligned along the ridges (D-F).
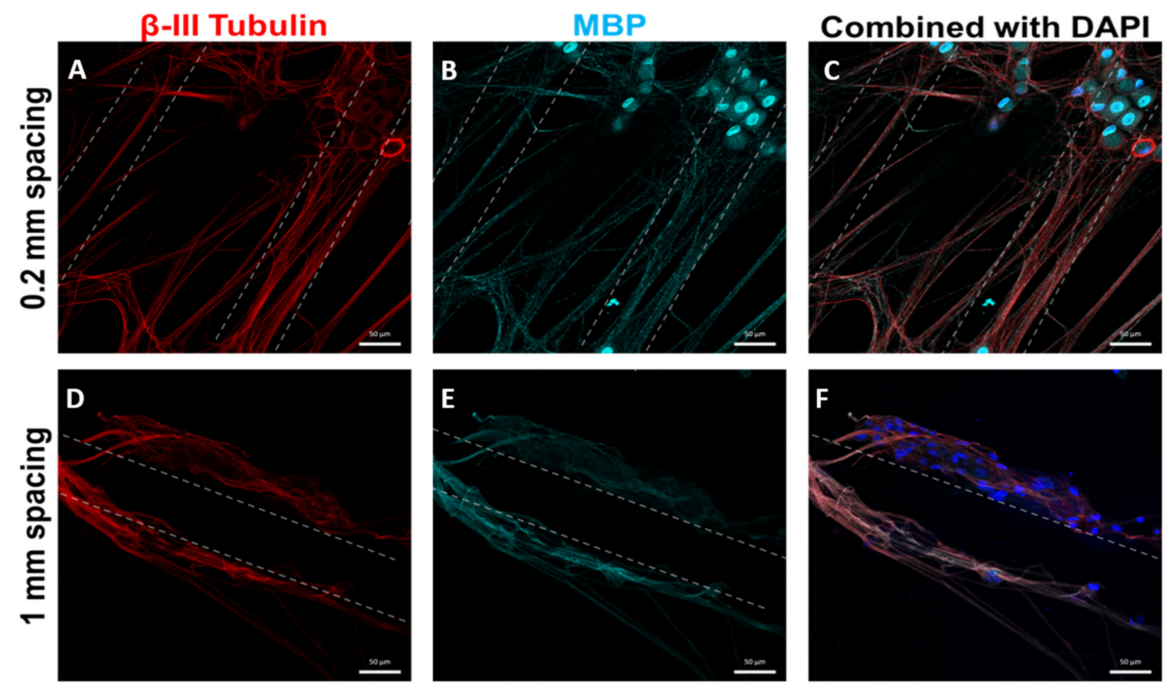

Figure 6. Confocal images showing Schwann cells co-cultured with disassociated DRG neuron on $\mathrm{OPF}+$ sheets with ridges spaced $0.2 \mathrm{~mm}$ or $1 \mathrm{~mm}$ apart. The cells were labeled with $\beta$-III tubulin staining (red, A,C,D,F), Myelin Basic Protein (teal, B,C,E,F), and DAPI (blue, C,F). After culture in media that supports myelination by Schwann cells, the Schwann cells myelinate the disassociated DRG neurites. Since alignment is enhanced by having the ridges on the OPF+ sheet closer together, it can be observed that there are more aligned myelinated neurites on the $0.2 \mathrm{~mm}$ spaced OPF+ sheets $(\mathbf{A}-\mathbf{C})$ than $1 \mathrm{~mm}$ spaced sheets $(\mathbf{D}, \mathbf{E})$. 


\section{Discussion}

We have previously demonstrated that $\mathrm{OPF}+$ fabricated in a multichannel design with seven channels can enhance regeneration after SCI $[4,7]$ in rats. This regeneration can be further improved by loading the channels with GDNF-secreting Schwann cells, leading to modest functional recovery [5]. We have also shown that the OPF+ material can be modified by incorporating the anti-fibrotic drug rapamycin in PLGA microspheres [27]. $\mathrm{OPF}+$ multichannel scaffolds containing rapamycin microspheres were also combined with Schwann cells to help promote functional recovery following SCI. It was also noted from these studies that many of the regenerating axons grew on the outer circumferential surface of the scaffold. Therefore, we hypothesized that axonal growth may preferentially occur on surfaces rather than within open spaces. Maximizing the surface areas available to regenerating axons to extend may further improve the density and directionality of regrowth as well as impact upon functional reconnections. In this study, we have now demonstrated in vitro that $\mathrm{OPF}+$ fabricated in a flat sheet design with ridges increased the surface area available for growth when compared to the multichannel design scaffold. Providing an attractive ECM protein coat and spacing, the ridges closer together improved cell attachment, outgrowth, and alignment of DRG explants, neurons, and Schwann cells.

When hydrated, the OPF+ sheets spontaneously form a 3D spiral tube. Hydrogels have been designed to self-roll in previous studies either by introducing reductants to cleave disulfide bonds [28], changes in $\mathrm{pH}$ and sacrificial layers [29], or using light responsive inks [30], photolithography [31], and magnetic nanorods [32]. These ridged scaffolds had swelling ratios comparable to our previous studies [9]. Hydrogels may suffer from low cell attachment due to the hydrated surface layer [33]. This issue could be addressed by coating the hydrogel sheets with collagen, laminin, or fibronectin, all of which are classically established as ECM coatings used to promote neurite outgrowth $[6,12,34,35]$. The current study shows that DRG explants cultured on laminin-coated OPF+ sheets had longer neurite outgrowth than fibronectin or collagen-coated sheets. In addition, the outgrowth rate of neurites on laminin-coated sheets was faster in the first $24 \mathrm{~h}$ of culture. This can be due to the different amount of proteins used or absorbed into the scaffold. Previous studies have demonstrated concentration-dependent differences in cell attachment and outgrowth; however, concentrations used in this study were within range of those used in other studies $[6,24,36,37]$. It is also interesting to note that the DRG outgrowth rate on the fibronectin-coated sheets was still increasing at the $24-48 \mathrm{~h}$ time point and may have results in greater outgrowth length at a later time point. When neuronal attachment was measured on or in between the ridges, laminin and fibronectin did equally well. The observed enhancement of neuronal outgrowth and guidance associated with laminin is in keeping with several other studies investigating different substrates for neuronal regeneration $[6,12,38]$. ECM proteins or their fragments play an important role in cell adhesion through ligand receptor interactions, and these interactions may be an important component to consider in developing novel biomaterials [39-41]. In addition, the three-dimensional structure of ECMs help anchor cells and provide axonal guidance [15]. We show that to maximize the ability of hydrogel scaffolds to anchor neurons and their axons and aid in their outgrowth, ECMs such as laminin and fibronectin are necessary to maximize the regenerative capability of the scaffold.

The combination of a scaffold containing ridges and ECM may mimic what is seen in development where topographical and chemical cues help guide axons. Factors such as the stiffness of the substrate can be important in determining the growth patterns of neurons, as shown by the growth of retinal ganglion cell axons toward softer tissue [42]. Laminin and $\beta$-integrin signaling have been found to be important in neuronal polarization and the deletion of $\beta$-integrin results in deficits in axonal development [43]. Radial glia, similar to the ridges of the scaffold, provide topographical cues that orientate the migration of embryonic neurons [44]. Neurite outgrowth from DRG explants and disassociated DRG neurons could be directed in a bidirectional way on ridged surfaces in this study. Ridges may provide important topographical cues, as the majority of neurons preferentially 
attached on or near the ridges of the scaffold. A similar preference for mechanical guidance cues (microgrooves), rather than on flat spaces between the microgrooves, has previously been observed [12]. Studies investigating the effect of grooves on a polymer surface have shown that axonal alignment and behavior could be influenced by the depth of the grooves, spacing between the grooves, and groove widths [12,38]. Similarly, in our study, disassociated DRG neurons that grew on the OPF+ sheets with ridges spaced $0.2 \mathrm{~mm}$ apart had greater cell attachment to the ridges, alignment, and outgrowth than those grown on $1 \mathrm{~mm}$ spaced sheets. One of the goals of the scaffold is to bridge the gap that is created after spinal cord injury. The ability of the scaffold to direct growth in a longitudinal direction and maximize this directed growth is an important consideration.

Another approach to enhancing regeneration is to mimic the peripheral nervous system environment. It is well established that the peripheral nervous system has a better ability to regenerate than the central nervous system. This may be due to a more rapid clearance and recycling of myelin debris, more permissive ECM, and a neurotrophic Schwann cell response [45]. The use of Schwann cells with biomaterials recreates a peripheral nervous system environment in the spinal cord, where the cells can contribute regenerative ECM, growth factors, and facilitate remyelination. Our lab, among others, has compared different cell types. Schwann cells have been found to be best able to support axonal regeneration $[10,26,46,47]$. In this study, Schwann cells preferentially organized along the ridges of $\mathrm{OPF}+$ sheets and myelinated neurites. The OPF+ sheet with ridges spaced $0.2 \mathrm{~mm}$ apart had more aligned myelinated neurites observable per area than the $1 \mathrm{~mm}$ sheet. This combination of the OPF+ ridged sheet with an ECM and Schwann cells may increase the regenerative potential of the scaffold, and these in vitro results suggest that this combination would be helpful in guiding and myelinating aligned axons.

This study demonstrates a novel hybrid design of the OPF+ scaffold for use in regenerative medicine, which is particularly suited for spinal cord injury. It has properties similar to the spinal cord, maximizes the available surface area and volume for regeneration, and can spontaneously roll to make a 3D structure for transplantation. Flattened, ridged sheets were used for in vitro studies and demonstrated improved neuron attachment, axonal alignment, and outgrowth. Furthermore, it would be straightforward to manufacture and scale for large animal studies and clinical applications. Scaffold properties can be modified including varying the ridge distance and size, as well as coating with different substances. It is also possible to study different cell types for different applications in regenerative medicine. This scaffold is well positioned to be used for combinatorial treatments to treat spinal cord injury through use of novel biomaterials, ECMs, and cells.

Supplementary Materials: The following are available online at https:/ /www.mdpi.com/article/10 .3390 /biomedicines $9050479 /$ s1, Figure S1.

Author Contributions: Conceptualization, J.E.S., J.S., A.J.W. and N.N.M.; methodology, A.M.S. (Ann M. Schmeichel), R.B., G.M.H., A.L.M.II, B.E.W. and N.N.M.; validation, A.M.S. (Ahad M. Siddiqui) and R.B.; formal analysis, A.M.S. (Ahad M. Siddiqui) and R.B.; investigation, A.M.S. (Ahad M. Siddiqui) and R.B.; resources, J.E.S., M.J.Y., A.J.W. and N.N.M.; data curation, A.M.S. (Ahad M. Siddiqui), R.B. and N.N.M.; writing-original draft preparation, A.M.S. (Ann M. Schmeichel), R.B. and N.N.M.; writing-review and editing, A.M.S. (Ahad M. Siddiqui), R.B., G.M.H., A.L.M.II, B.E.W., J.E.S., J.S., M.J.Y., A.J.W. and N.N.M.; visualization, A.M.S. (Ahad M. Siddiqui), R.B. and NNM; supervision, J.E.S., J.S., M.J.Y., A.J.W. and N.N.M.; project administration, J.E.S., J.S., A.J.W. and N.N.M.; funding acquisition, J.E.S., J.S., A.J.W. and N.N.M. All authors have read and agreed to the published version of the manuscript.

Funding: This publication was supported by Grants from the New Jersey Commission on Spinal Cord Research CSCR15IRG002 and the National Center for Advancing Translational Sciences (NCATS) UL1 TR002377 and TL1 TR002380. It was also supported by grants from Regenerative Medicine Minnesota and the Bowen Foundation, the Kipnis Foundation and the Mayo Clinic Center for Regenerative Medicine. 
Institutional Review Board Statement: All procedures were approved by the Mayo Clinic Institutional Animal Care and Use Committee (A00002147-16, last approved: 8/30/2019), and all guidelines were followed in accordance with the National Institute of Health, Institute for Laboratory Animal Research and the United States Public Health Services Policy on the Humane Care and Use of Laboratory Animals.

Informed Consent Statement: Not Applicable.

Data Availability Statement: Data available upon reasonable request.

Acknowledgments: The authors would like to acknowledge Jewel Podratz with training and assistance with primary cell culture of DRGs. This publication was supported by Grants from the New Jersey Commission on Spinal Cord Research CSCR15IRG002 and the National Center for Advancing Translational Sciences (NCATS) UL1 TR002377 and TL1 TR002380. It was also supported by grants from Regenerative Medicine Minnesota and the Bowen Foundation, the Kipnis Foundation and the Mayo Clinic Center for Regenerative Medicine.

Conflicts of Interest: The authors declare no conflict of interest.

\section{References}

1. Siddiqui, A.M.; Khazaei, M.; Fehlings, M.G. Translating mechanisms of neuroprotection, regeneration, and repair to treatment of spinal cord injury. Prog. Brain Res. 2015, 218, 15-54.

2. Badner, A.; Siddiqui, A.M.; Fehlings, M.G. Spinal cord injuries: How could cell therapy help? Expert Opin. Biol. Ther. 2017, 17, 529-541. [CrossRef] [PubMed]

3. Madigan, N.N.; McMahon, S.; O’Brien, T.; Yaszemski, M.J.; Windebank, A.J. Current tissue engineering and novel therapeutic approaches to axonal regeneration following spinal cord injury using polymer scaffolds. Respir. Physiol. Neurobiol. 2009, 169, 183-199. [CrossRef]

4. Hakim, J.S.; Esmaeili Rad, M.; Grahn, P.J.; Chen, B.K.; Knight, A.M.; Schmeichel, A.M.; Isaq, N.A.; Dadsetan, M.; Yaszemski, M.J.; Windebank, A.J. Positively charged oligo [poly (ethylene glycol) fumarate] scaffold implantation results in a permissive lesion environment after spinal cord injury in rat. Tissue Eng. Part A 2015, 21, 2099-2114. [CrossRef]

5. Chen, B.K.; Madigan, N.N.; Hakim, J.S.; Dadsetan, M.; McMahon, S.S.; Yaszemski, M.J.; Windebank, A.J. GDNF Schwann cells in hydrogel scaffolds promote regional axon regeneration, remyelination and functional improvement after spinal cord transection in rats. J. Tissue Eng. Regen. Med. 2018, 12, e398-e407. [CrossRef]

6. Harris, G.M.; Madigan, N.N.; Lancaster, K.Z.; Enquist, L.W.; Windebank, A.J.; Schwartz, J.; Schwarzbauer, J.E. Nerve Guidance by a Decellularized Fibroblast Extracellular Matrix. Matrix Biol. 2017, 60, 176-189. [CrossRef] [PubMed]

7. Chen, B.K.; Knight, A.M.; Madigan, N.N.; Gross, L.; Dadsetan, M.; Nesbitt, G.E.; Rooney, J.J.; Currier, B.L.; Yaszemski, M.J.; Spinner, R.J. Comparison of polymer scaffolds in rat spinal cord: A step toward quantitative assessment of combinatorial approaches to spinal cord repair. Biomaterials 2011, 32, 8077-8086. [CrossRef] [PubMed]

8. Dadsetan, M.; Szatkowski, J.P.; Yaszemski, M.J.; Lu, L. Characterization of photo-cross-linked oligo [poly (ethylene glycol) fumarate] hydrogels for cartilage tissue engineering. Biomacromolecules 2007, 8, 1702-1709. [CrossRef]

9. Dadsetan, M.; Knight, A.M.; Lu, L.; Windebank, A.J.; Yaszemski, M.J. Stimulation of neurite outgrowth using positively charged hydrogels. Biomaterials 2009, 30, 3874-3881. [CrossRef] [PubMed]

10. Madigan, N.N.; Chen, B.K.; Knight, A.M.; Rooney, G.E.; Sweeney, E.; Kinnavane, L.; Yaszemski, M.J.; Dockery, P.; O’Brien, T.; McMahon, S.S. Comparison of cellular architecture, axonal growth, and blood vessel formation through cell-loaded polymer scaffolds in the transected rat spinal cord. Tissue Eng. Part A 2014, 20, 2985-2997. [CrossRef]

11. Clark, P.; Connolly, P.; Curtis, A.; Dow, J.; Wilkinson, C. Cell guidance by ultrafine topography in vitro. J. Cell Sci. 1991, 99, 73-77. [CrossRef] [PubMed]

12. Yao, L.; Wang, S.; Cui, W.; Sherlock, R.; O'Connell, C.; Damodaran, G.; Gorman, A.; Windebank, A.; Pandit, A. Effect of functionalized micropatterned PLGA on guided neurite growth. Acta Biomater. 2009, 5, 580-588. [CrossRef] [PubMed]

13. Barillé, R.; Janik, R.; Kucharski, S.; Eyer, J.; Letournel, F. Photo-responsive polymer with erasable and reconfigurable micro- and nano-patterns: An in vitro study for neuron guidance. Colloids Surf. B Biointerfaces 2011, 88, 63-71. [CrossRef] [PubMed]

14. Goldner, J.S.; Bruder, J.M.; Li, G.; Gazzola, D.; Hoffman-Kim, D. Neurite bridging across micropatterned grooves. Biomaterials 2006, 27, 460-472. [CrossRef] [PubMed]

15. Haggerty, A.E.; Marlow, M.M.; Oudega, M. Extracellular matrix components as therapeutics for spinal cord injury. Neurosci. Lett. 2017, 652, 50-55. [CrossRef]

16. Yao, L.; Damodaran, G.; Nikolskaya, N.; Gorman, A.M.; Windebank, A.; Pandit, A. The effect of laminin peptide gradient in enzymatically cross-linked collagen scaffolds on neurite growth. J. Biomed. Mater. Res. Part A 2010, 92, 484-492. [CrossRef]

17. Adams, D.N.; Kao, E.Y.C.; Hypolite, C.L.; Distefano, M.D.; Hu, W.S.; Letourneau, P.C. Growth cones turn and migrate up an immobilized gradient of the laminin IKVAV peptide. Dev. Neurobiol. 2005, 62, 134-147. [CrossRef] 
18. Baron-Van Evercooren, A.; Kleinman, H.K.; Seppä, H.; Rentier, B.; Dubois-Dalcq, M. Fibronectin promotes rat Schwann cell growth and motility. J. Cell Biol. 1982, 93, 211-216. [CrossRef]

19. Mosahebi, A.; Wiberg, M.; Terenghi, G. Addition of fibronectin to alginate matrix improves peripheral nerve regeneration in tissue-engineered conduits. Tissue Eng. 2003, 9, 209-218. [CrossRef]

20. Lin, C.-Y.; Lee, Y.-S.; Lin, V.W.; Silver, J. Fibronectin inhibits chronic pain development after spinal cord injury. J. Neurotrauma 2012, 29, 589-599. [CrossRef]

21. Novikova, L.N.; Novikov, L.N.; Kellerth, J.-O. Biopolymers and biodegradable smart implants for tissue regeneration after spinal cord injury. Curr. Opin. Neurol. 2003, 16, 711-715. [CrossRef]

22. Conti, A.M.; Fischer, S.J.; Windebank, A.J. Inhibition of axonal growth from sensory neurons by excess nerve growth factor. Ann. Neurol. 1997, 42, 838-846. [CrossRef] [PubMed]

23. Ta, L.E.; Espeset, L.; Podratz, J.; Windebank, A.J. Neurotoxicity of oxaliplatin and cisplatin for dorsal root ganglion neurons correlates with platinum-DNA binding. Neurotoxicology 2006, 27, 992-1002. [CrossRef]

24. Podratz, J.L.; Windebank, A.J. NGF rescues DRG neurons in vitro from oxidative damage produced by hemodialyzers Neurotoxicology 2005, 26, 343-350. [CrossRef] [PubMed]

25. Chen, B.K.; Knight, A.M.; De Ruiter, G.C.; Spinner, R.J.; Yaszemski, M.J.; Currier, B.L.; Windebank, A.J. Axon regeneration through scaffold into distal spinal cord after transection. J. Neurotrauma 2009, 26, 1759-1771. [CrossRef] [PubMed]

26. Olson, H.E.; Rooney, G.E.; Gross, L.; Nesbitt, J.J.; Galvin, K.E.; Knight, A.; Chen, B.; Yaszemski, M.J.; Windebank, A.J. Neural stem cell-and schwann cell-loaded biodegradable polymer scaffolds support axonal regeneration in the transected spinal cord. Tissue Eng. Part A 2009, 15, 1797-1805. [CrossRef] [PubMed]

27. Hakim, J.; Rodysill, B.; Chen, B.K.; Schmeichel, A.; Yaszemski, M.J.; Windebank, A.; Madigan, N. Combinatorial Tissue Engineering Partially Restores Function after Spinal Cord Injury. J. Tissue Eng. Regen. Med. 2019, 13, 857-873. [CrossRef]

28. Liu, L.; Wang, N.; Han, Y.; Li, Y.; Liu, W. Redox-Triggered Self-Rolling Robust Hydrogel Tubes for Cell Encapsulation. Macromol. Rapid Commun. 2014, 35, 344-349. [CrossRef] [PubMed]

29. Vasiev, I.; Greer, A.I.M.; Khokhar, A.Z.; Stormonth-Darling, J.; Tanner, K.E.; Gadegaard, N. Self-folding nano- and micropatterned hydrogel tissue engineering scaffolds by single step photolithographic process. Microelectron. Eng. 2013, 108, 76-81. [CrossRef]

30. Zhang, Q.; Wommer, J.; O’Rourke, C.; Teitelman, J.; Tang, Y.; Robison, J.; Lin, G.; Yin, J. Origami and kirigami inspired self-folding for programming three-dimensional shape shifting of polymer sheets with light. Extrem. Mech. Lett. 2017, 11, 111-120. [CrossRef]

31. Thérien-Aubin, H.l.; Wu, Z.L.; Nie, Z.; Kumacheva, E. Multiple shape transformations of composite hydrogel sheets. J. Am. Chem. Soc. 2013, 135, 4834-4839. [CrossRef]

32. Guo, H.; Zhang, Q.; Liu, W.; Nie, Z. Light-Mediated Shape Transformation of a Self-Rolling Nanocomposite Hydrogel Tube. ACS Appl. Mater. Interfaces 2020, 12, 13521-13528. [CrossRef] [PubMed]

33. Gombotz, W.R.; Wang, G.H.; Horbett, T.A.; Hoffman, A.S. Protein adsorption to poly(ethylene oxide) surfaces. J. Biomed. Mater. Res. 1991, 25, 1547-1562. [CrossRef]

34. Dodla, R.V.; Bellamkonda, M.C. Anisotropic scaffolds facilitate enhanced neurite extension in vitro. J. Biomed. Mater. Res. A 2006, 78, 213-221. [CrossRef]

35. Besser, R.R.; Bowles, A.C.; Alassaf, A.; Carbonero, D.; Claure, I.; Jones, E.; Reda, J.; Wubker, L.; Batchelor, W.; Ziebarth, N.; et al. Enzymatically crosslinked gelatin-laminin hydrogels for applications in neuromuscular tissue engineering. Biomater. Sci. 2020, 8 , 591-606. [CrossRef] [PubMed]

36. Sevilla, C.A.; Dalecki, D.; Hocking, D.C. Extracellular matrix fibronectin stimulates the self-assembly of microtissues on native collagen gels. Tissue Eng. Part A 2010, 16, 3805-3819. [CrossRef]

37. Deister, C.; Aljabari, S.; Schmidt, C.E. Effects of collagen 1, fibronectin, laminin and hyaluronic acid concentration in multicomponent gels on neurite extension. J. Biomater. Sci. Polym. Ed. 2007, 18, 983-997. [CrossRef]

38. Miller, C.; Jeftinija, S.; Mallapragada, S. Synergistic effects of physical and chemical guidance cues on neurite alignment and outgrowth on biodegradable polymer substrates. Tissue Eng. 2002, 8, 367-378. [CrossRef]

39. Ma, Z.; Mao, Z.; Gao, C. Surface modification and property analysis of biomedical polymers used for tissue engineering. Colloids Surf. B Biointerfaces 2007, 60, 137-157. [CrossRef] [PubMed]

40. Levesque, S.G.; Shoichet, M.S. Synthesis of cell-adhesive dextran hydrogels and macroporous scaffolds. Biomaterials 2006, 27, 5277-5285. [CrossRef] [PubMed]

41. Dodla, M.C.; Bellamkonda, R.V. Differences between the effect of anisotropic and isotropic laminin and nerve growth factor presenting scaffolds on nerve regeneration across long peripheral nerve gaps. Biomaterials 2008, 29, 33-46. [CrossRef] [PubMed]

42. Koser, D.E.; Thompson, A.J.; Foster, S.K.; Dwivedy, A.; Pillai, E.K.; Sheridan, G.K.; Svoboda, H.; Viana, M.; da, F. Costa, L.; Guck, J. Mechanosensing is critical for axon growth in the developing brain. Nat. Neurosci. 2016, 19, 1592. [CrossRef]

43. Lei, W.-L.; Xing, S.-G.; Deng, C.-Y.; Ju, X.-C.; Jiang, X.-Y.; Luo, Z.-G. Laminin/ $\beta 1$ integrin signal triggers axon formation by promoting microtubule assembly and stabilization. Cell Res. 2012, 22, 954. [CrossRef] [PubMed]

44. Hatten, M.E. Riding the glial monorail: A common mechanism for glialguided neuronal migration in different regions of the developing mammalian brain. Trends Neurosci. 1990, 13, 179-184. [CrossRef]

45. Siddiqui, A.M.; Ahuja, C.S.; Tator, C.H.; Fehlings, M.G. Chapter 3: Spinal cord protective and regenerative therapies. In Neurotrauma and Critical Care of the Spine, 2nd ed.; Jallo, J., Vaccaro, A., Eds.; Thieme: New York, NY, USA, 2018 ; p. 238. 
46. Rooney, G.E.; Knight, A.M.; Madigan, N.N.; Gross, L.; Chen, B.; Giraldo, C.V.; Seo, S.; Nesbitt, J.J.; Dadsetan, M.; Yaszemski, M.J. Sustained delivery of dibutyryl cyclic adenosine monophosphate to the transected spinal cord via oligo [(polyethylene glycol) fumarate] hydrogels. Tissue Eng. Part A 2011, 17, 1287-1302. [CrossRef] [PubMed]

47. Xu, X.M.; Guénard, V.; Kleitman, N.; Bunge, M.B. Axonal regeneration into Schwann cell-seeded guidance channels grafted into transected adult rat spinal cord. J. Comp. Neurol. 1995, 351, 145-160. [CrossRef] 